\title{
Selective Hippocampal Lesions Do Not Increase Adrenocortical Activity
}

\author{
Frode A. Tuvnes, ${ }^{1}$ Hill-Aina Steffenach, ${ }^{1}$ Robert Murison, ${ }^{2}$ May-Britt Moser, ${ }^{1}$ and Edvard I. Moser ${ }^{1}$ \\ ${ }^{1}$ Centre for the Biology of Memory, Norwegian University of Science and Technology, N-7489 Trondheim, Norway, and ${ }^{2}$ Department of Biological and \\ Medical Psychology, University of Bergen, 5009 Bergen, Norway
}

It has been proposed that the hippocampus exerts a tonic inhibitory influence on the hypothalamic-pituitary-adrenal (HPA) stress axis. This claim rests, in particular, on the upregulation of corticosterone secretion and other measures of HPA activity after nonselective lesions of the hippocampal formation. We measured plasma corticosterone concentrations after selective neurotoxic damage to the hippocampus and the subiculum in rats. Concentrations were estimated during rest in the rat's home cage and at several time points after varying degrees of stress. Lesions of the hippocampus did not increase the concentration of corticosterone relative to control rats in any condition. Temporary inactivation of the hippocampus or the ventral subiculum by infusion of the $\mathrm{GABA}_{\mathrm{A}}$ receptor agonist muscimol also failed to induce hypersecretion, although hippocampal infusions did impair spatial memory. These results suggest that the hippocampus is not necessary for tonic inhibition of adrenocortical activity and imply that the HPA axis receives efficient negative feedback inhibition from other brain systems too.

Key words: hippocampus; corticosterone; endocrine; adrenocortical; stress; HPA axis; learning; memory; rat

\section{Introduction}

Stress triggers a cascade of physiological events in the hypothalamic-pituitary-adrenal (HPA) axis resulting ultimately in the release of glucocorticoids in excess of the normal circadian secretion (Selye, 1936; Jacobson and Sapolsky, 1991; Herman and Cullinan, 1997). The secretion is initiated with the release of corticotrophin-releasing hormone $(\mathrm{CRH})$. CRH is released in the portal system of the median eminence from the parvocellular part of the paraventricular nucleus of the hypothalamus. CRH stimulates the secretion of adrenocorticotropic hormone (ACTH) from corticotrophs in the anterior pituitary gland. ACTH is secreted into the general circulation, which results in stimulation of glucocorticoid secretion from the adrenal cortex. In rats, the major adrenal steroid secreted is corticosterone (CORT). The increase of plasma corticosterone reaches an asymptote $\sim 15$ min after exposure to a stressful stimulus (Brett et al., 1983).

The hippocampus has received considerable attention as a potential negative feedback regulator of the HPA axis (Jacobson and Sapolsky, 1991), because the structure contains a high density of corticosteroid receptors (McEwen et al., 1968; Aronsson et al., 1988; Arriza et al., 1988) and because the hippocampal formation has projections back to the paraventricular nucleus of the hypothalamus (Risold et al., 1997; Petrovich et al., 2001). Physiological evidence from various sources indicates that hippocampal activity exerts an inhibitory influence on the HPA axis (Jacobson and Sapolsky, 1991), but does normal HPA activity depend on this hippocampal input or can other control systems provide

Received Dec. 2, 2002; revised Feb. 12, 2003; accepted Feb. 24, 2003

This work was by the Norwegian Research Council (Grants 122512/310 and 133958/420). We thank R. Espelid, I. Hammer, K. Haugen, K. Jenssen, E. Nordeide, and R. Ulriksen for technical assistance.

Correspondence should be addressed to Edvard I. Moser, Centre for the Biology of Memory, Medical-Technical Research Centre, Norwegian University of Science and Technology, Olav Kyrres gate 3, N-7489 Trondheim, Norway. E-mail: edvard.moser@cbm.ntnu.no.

Copyright $\odot 2003$ Society for Neuroscience $\quad$ 0270-6474/03/234345-10\$15.00/0 similar inhibition? Several studies have shown that damage to the hippocampus increases basal glucocorticoid secretion (Fendler et al., 1961; Kim and Kim, 1961; Knigge, 1961; Moberg et al., 1971; Fischette et al., 1980; Wilson et al., 1980; Sapolsky et al., 1984, 1991; Herman et al., 1989), but these lesions were made either by aspiration or by transection of the fimbria-fornix and caused damage to bypassing fibers as well as adjacent brain systems, including the parahippocampal cortices and several subcortical structures. Other studies failed to identify a hippocampal inhibitory influence on the HPA axis (Coover et al., 1971; Lanier et al., 1975; Conforti and Feldman, 1976; Smotherman et al., 1981; Bradbury et al., 1993; Herman et al., 1995) but there was only incomplete damage to the hippocampus in these studies. The remaining tissue may have been sufficient to maintain hippocampal feedback inhibition of the HPA axis. To examine whether the hippocampus plays a necessary role in inhibition of HPA activity, we measured plasma corticosterone concentrations after complete axon-sparing lesions of this structure. Rats with ibotenate lesions of the hippocampus were compared with unoperated rats, rats with sham lesions, and rats with ibotenate lesions restricted to the dorsal or ventral hippocampus. Because some studies show that nonselective damage to the hippocampal formation exacerbates corticosterone secretion during restraint stress but leaves basal concentrations unaffected (Murphy et al., 1979; Herman et al., 1995, 1998), we estimated the concentration of corticosterone both during rest and at multiple time points after exposure to a stressor.

\section{Materials and Methods}

Subjects. A total of 194 male Long-Evans rats (250-450 gm; Taconic M \& $B$, Ry, Denmark) were housed in groups of two to five in large transparent polycarbonate cages $(59 \times 38 \times 20 \mathrm{~cm})$ with food and water available $a d$ libitum. The rats were maintained on a $12 \mathrm{hr}$ light/dark cycle (lights on at 8 A.M.) in a temperature- and humidity-controlled room. All behavioral training occurred during the light phase of the circadian cycle. Cortico- 
Table 1. Stereotaxic coordinates for ibotenate lesions of the hippocampus

\begin{tabular}{lll}
\hline AP & ML & DV \\
\hline-2.4 & \pm 1.0 & $-3.0^{*}$ \\
-3.0 & \pm 1.4 & -2.9 and -2.1 \\
-3.0 & \pm 3.0 & $-2.7^{* *}$ \\
-3.8 & \pm 2.6 & -2.7 and -1.8 \\
-3.8 & \pm 3.7 & $-2.7^{* *}$ \\
-4.4 & \pm 3.8 & $-7.0^{*}$ \\
-4.4 & \pm 4.1 & $-3.5^{*}$ \\
-4.4 & \pm 4.4 & $-6.3^{* *}$ \\
-5.2 & \pm 4.3 & $-4.2^{* *}$ \\
-5.2 & \pm 5.0 & $-5.9^{* *},-5.2^{* *}$ and $-4.5^{* *}$
\end{tabular}

Coordinates are relative to bregma ( $\mathrm{AP}$, anteroposterior; $\mathrm{ML}$, mediolateral; $\mathrm{DV}$, dorsoventral). The volume of ibotenic acid injected was $0.05 \mu \mathrm{l}$ (no asterisk), $0.07-0.08 \mu \mathrm{l}$ (one asterisk), or $0.10 \mu \mathrm{l}$ (two asterisks). Bregma and lambda were on the same horizontal plane. DV coordinates are relative to dura at AP $-4.8, \mathrm{ML} \pm 4.1$.

sterone was sampled during the first half of the light phase (10 A.M.-3 P.M.), at the nadir of the circadian cyclus of corticosterone secretion. Only the experimenter had access to the vivarium before 3 P.M. on these days.

Surgery. The rats were anesthetized with Equithesin (pentobarbital and chloral hydrate; $1.0 \mathrm{ml} / 250$ gm body weight). Hippocampal lesions were made by bilateral injection of ibotenic acid (Sigma-Aldrich, Oslo, Norway) at multiple locations (Jarrard, 1989). Ibotenic acid was dissolved in PBS, $\mathrm{pH} 7.4$, at $10 \mathrm{mg} / \mathrm{ml}$ and injected through a $1 \mu \mathrm{l} \mathrm{Hamilton}$ syringe mounted to the stereotaxic frame. Injections of $0.05-0.10 \mu \mathrm{l}$ were made over 10-20 sec at each site (Table 1). The syringe was retracted 2 min after each injection. Lesions were either complete $(n=47)$ or partial (dorsal lesions: $n=25$; ventral lesions: $n=15$ ). In sham-operated rats, the syringe was lowered through the neocortex, but no drug was infused $(n=57)$. Eight rats received no surgical treatment.

In addition, 32 rats were prepared for temporary inactivation of the hippocampus. Sixteen of these were implanted with four 26 ga guide cannulas (C315G; Plastics One), two in each hippocampus (pair 1: 2.24 $\mathrm{mm}$ behind bregma, $2.8 \mathrm{~mm}$ lateral to the midline, and $1,5 \mathrm{~mm}$ below dura; pair 2: $5.0 \mathrm{~mm}$ behind bregma, $4.3 \mathrm{~mm}$ lateral, $4.1 \mathrm{~mm}$ below dura). The remaining 16 received one cannula in each hippocampus $(4.4 \mathrm{~mm}$ behind bregma, $4.1 \mathrm{~mm}$ lateral, $2.6 \mathrm{~mm}$ below dura). An additional group of 10 rats were implanted with a cannula in the ventral subiculum (one in each hemisphere; $6.3 \mathrm{~mm}$ behind bregma, $5.0 \mathrm{~mm}$ lateral, $5.0 \mathrm{~mm}$ below dura). Cannulas and anchor screws were encased in dental acrylic.

Blood sampling procedure. Blood was sampled after rest in the vivarium or after exposure to stressors of different intensity. The rat was brought to the procedure room and put directly into a small chamber with anesthetic (Fluothane or Isofluran). Anesthesia was induced within 10-15 sec and maintained with a cup of cotton sprinkled with Fluothane held over the rat's mouth and nose by one experimenter. The respiration rate was examined constantly. A second experimenter collected 1 or $2 \mathrm{ml}$ of blood from vena jugularis (after exposure to stressors) or from the heart (after rest in the home cage). Blood was sampled using either one or two heparinized $1 \mathrm{ml}$ syringes (from vena jugularis) or one heparinized $2 \mathrm{ml}$ syringe (from the heart) and a hypodermic needle $(0.8 \times 40 \mathrm{~mm}$; Microlance). It took 2-3 min from the time the rat was picked up until blood sampling was completed. After collection of the blood, the rat was anesthetized with Equithesin $(0.7 \mathrm{ml} / 250$ gm body weight, i.p. $)$ and sewn together (vena jugularis samples) or perfused intracardially with saline and $4 \%$ formaldehyde (intracardial samples). The blood was transferred to centrifuge tubes ( $2 \mathrm{ml}$ Nalge Nunc), and plasma was obtained by centrifugation at $6000 \mathrm{rpm}$ for $15 \mathrm{~min}$ (Sorwall, MC $12 \mathrm{~V}$, DuPont) and stored at $-20^{\circ} \mathrm{C}$. Plasma corticosterone concentrations were determined by radioimmunoassay using commercial kits (Diagnostic Products Corporation, Los Angeles, CA).

Behavioral procedures. Blood was first sampled during three conditions that varied in stress intensity. This study included 21 rats with complete hippocampal lesions, 40 rats with partial lesions, and 24 sham-operated rats. The initial sample was taken 2 weeks after surgery. Rats were placed individually into a white, brightly lit Perspex box $(50 \times 50 \times 50 \mathrm{~cm} ; 1000$ lux) that they had explored daily for 20 min during the preceding $5 \mathrm{~d}$ ( 10 min in the morning, $10 \mathrm{~min}$ in the afternoon). The floor of the box was a grid of 21 bars. The bars were $8 \mathrm{~mm}$ in diameter and $2.2 \mathrm{~cm}$ apart (center to center). After the rat had been left in the box for $20 \mathrm{~min}$, it was brought in a familiar transport cage to the procedure room for the first blood sample. Before the next animal was tested, the interior of the Perspex box was cleaned with damp tissue paper. Tissue paper was never reused.

One week later, the same rats were exposed to the Perspex box on 2 consecutive days under more stressful conditions. The box was in the same place on both days. On day 1 , the rats received three electric shocks to the foot. Alternate bars were connected to the positive and negative poles of a stimulator (Pulsar, Axona Ltd., Herts, UK). Shocks ( $1 \mathrm{~mA}$ for 1 sec) were given after 3, 5, and $7 \mathrm{~min}$. On day 2, the rats were placed in the box, but no shock was delivered. Behavior was video-recorded and tracked (Watermaze Software, University of Edinburgh, UK). Stress was estimated by scoring freezing for $5 \mathrm{~min}$ (one score every $10 \mathrm{sec}$ ). Freezing was defined as the complete absence of movement except that required for respiratory purposes. Scoring of freezing was highly correlated between two observers ( $r=0.98 ; n=9$ rats). After 20 min of confinement, the animals were transported directly to the procedure room for the second blood sample.

Finally, $4 \mathrm{~d}$ later, the resting concentration of corticosterone was measured in the same rats. The rats were transported individually in a familiar cage from the vivarium to the procedure room, which was $5 \mathrm{~m}$ away.

A separate group of animals was tested with the same stress protocols as used in previous reports (Sapolsky et al., 1984; Roozendaal et al., 2001). Rats received either complete hippocampal lesions $(n=8)$ or sham surgery $(n=8)$. Blood was sampled on three occasions: first after immobilization in a restraint tube (days 10-14 after surgery), then after 60 sec of free swimming in a Morris water maze (days 18-22), and finally after rest in the vivarium (days 25-29). Restraint tubes were cylindrical (length $21 \mathrm{~cm}$; diameter $6 \mathrm{~cm}$ ), were closed with wire mesh at one end and metal bolts at the other, and had walls of plastic. Tubes were not reused; each animal received a different tube. Rats were immobilized for $1 \mathrm{hr}$ in the restraint tubes. Training in the water maze consisted of four trials with the escape platform at a constant location on each of 2 consecutive days. Training was conducted in a white circular polyvinylchloride tank (198 cm diameter, $50 \mathrm{~cm}$ deep) filled to a depth of $40 \mathrm{~cm}$ with water at $25 \pm 2{ }^{\circ} \mathrm{C}$ (Moser and Moser, 1998). The diameter of the escape platform was $29.5 \mathrm{~cm}$. Rats spent $10 \mathrm{sec}$ on the platform after each trial and were then placed in a holding cage for $20 \mathrm{sec}$ before the next trial. A retention test with the platform in an unavailable position (at the bottom of the pool) was conducted at the beginning of day 3 . After $60 \mathrm{sec}$, the remotely controlled platform was raised to a level $1 \mathrm{~cm}$ below the water surface, and the rat was allowed to escape. The position of the rat was tracked at $50 \mathrm{~Hz}$ (Axona Ltd.). Blood was sampled after the final retention test. The rats rested in the vivarium until 2-3 min before the start of the retention trial. After escape, they were brought directly to the procedure room, as in Roozendaal et al. (2001).

To examine the duration of the corticosterone response, we prepared a separate group of rats with complete hippocampal lesions $(n=10)$ or sham lesions $(n=9)$. These animals were placed into the Perspex box on three sessions, with an interval of $6 \mathrm{~d}$ between each session. On each occasion, the rat spent $5 \mathrm{~min}$ in the box. The rat was then carried back to the vivarium where it rested in its home cage until 30,60, or $90 \mathrm{~min}$ had passed since the start of the box session. At the completion of the interval, the rat was brought to the procedure room for collection of blood. The order of the intervals was counterbalanced across the three test sessions.

Nonspecific effects of surgery. All rats including the sham group received intracranial surgery, which might influence the HPA system for a long time. To determine whether the surgery caused nonspecific changes in adrenocortical activity, we compared the resting levels of corticosterone in a separate group of rats with sham lesions $(n=8)$ and a group of naive, unoperated littermates $(n=8)$. Blood was collected $18 \mathrm{~d}$ after surgery in the sham group. This interval is comparable with the interval used in the other experiments of the present study.

Effect of recovery after surgery. To examine whether hippocampal lesions elevated corticosterone levels only at short intervals after surgery, we prepared a separate group of eight rats with complete hippocampal lesions and eight rats with sham lesions. Blood was sampled on day 4 after 
surgery and again on day 7. Before sampling, the animals were placed in a brightly lit novel chamber (1000 lux). Blood was sampled $30 \mathrm{~min}$ after the start of the session on one of the days and $90 \mathrm{~min}$ after start on the other day. The order was counterbalanced. The rats remained in the chamber during the entire interval. Different chambers were used on the $2 \mathrm{~d}$.

Temporary inactivation. The hippocampus was temporarily inactivated in rats with implanted cannulas by bilateral intrahippocampal infusion of the $\mathrm{GABA}_{\mathrm{A}}$ receptor agonist 5-aminomethyl-3-hydroxyisoxazole (muscimol; Sigma) dissolved in PBS, pH 7.4 (0.5 $\mu \mathrm{g} / \mu \mathrm{l})$. Muscimol was infused into the hippocampus on two occasions in each of 16 rats (8 with one cannula, 8 with two cannulas): before testing in the water maze and before collection of blood ( $2 \mathrm{~d}$ after the water-maze test). Control rats $(n=16)$ received equivalent injections of saline. Blood was sampled from the heart as above.

Muscimol was infused via a 33 ga internal cannula (C315I; Plastics One) with the tip protruding $0.9 \mathrm{~mm}$ beyond the implanted guide cannula. The total volume of each hippocampal infusion was $0.25 \mu \mathrm{l}$. A syringe pump controlled the infusion rate $(0.08 \mu \mathrm{l} / \mathrm{min}$ in rats with two cannulas; $0.16 \mu \mathrm{l} / \mathrm{min}$ with four cannulas). Control rats received saline (same volume and same rate). The internal cannula was retracted $2 \mathrm{~min}$ after each infusion. After the last infusion, the rat was carried back to the vivarium where it rested for $1 \mathrm{hr}$ before it was tested in the water maze or anesthetized for collection of blood.

In a second inactivation experiment, muscimol or saline was infused into the ventral subiculum $(n=10)$, using the same infusion procedure as for hippocampal inactivation with a single cannula, except that the volume was increased to $0.40 \mu \mathrm{l}$ per injection. Each animal received two infusions, one with muscimol and one with saline, at an interval of 1 week. The first infusion was made 2 weeks after surgery. The order of the infusions was counterbalanced. After each infusion, the rats were brought back to the vivarium. Blood was sampled $1 \mathrm{hr}$ later.

Effect of muscimol on hippocampal-dependent learning. To determine whether muscimol successfully inactivated the hippocampus, we tested the effect of the drug on a known hippocampal function: retention of spatial memory in a Morris water maze (Morris et al., 1982; Moser and Moser, 1998). Before the infusion, the animals had been trained to search for a hidden escape platform $(11 \mathrm{~cm}$ diameter $)$ at a fixed position in the pool described above. They were trained twice daily for $7 \mathrm{~d}$ (four trials per session, $4 \mathrm{hr}$ inter-session interval), except on the first day, when they received only one session. Retention was tested on a $60 \mathrm{sec}$ probe trial at the end of training. On the basis of search time in the target zone (circle with radius of $35 \mathrm{~cm}$ around the platform), the rats were ranked, matched, and assigned to the drug group or a control group. Two hours later, muscimol or saline was infused into each hippocampus, and $1 \mathrm{hr}$ after the infusion, a second identical retention trial was conducted. At the end of this trial, the platform was raised in the opposite quadrant of the pool. The rats were retrained with this new platform location on subsequent trials (four blocks of two trials; inter-block interval $10 \mathrm{~min}$; probe test $30 \mathrm{~min}$ after the last block).

Histology. The rats were perfused intracardially with saline and $4 \%$ formaldehyde. The brains were stored in $4 \%$ formaldehyde for at least 1 week, after which they were quickly frozen and cut in coronal sections of $30 \mu \mathrm{m}$ thickness on a cryostat. In the lesion study, every 10th section was retained, mounted, and stained with cresyl violet. In the inactivation study, every second section was retained in the area around the cannula. The volume of residual hippocampal and subicular tissue was determined from digital images of each brain section as described previously (Moser and Moser, 1998). The volumes were expressed as percentages of the corresponding volumes in the sham-operated group.

\section{Results \\ Histology}

Animals in the complete lesion group had extensive lesions of the hippocampus that included dentate gyrus, hippocampus proper, and subiculum (Fig. 1A,B). The spared tissue corresponded to $4.3 \pm 0.9 \%$ of the total volume of the hippocampus and $15.5 \pm$ $4.4 \%$ of the subiculum (means \pm SEM). Additional rats had lesions aimed at the dorsal or ventral two-thirds of the hippocam- pus. These lesions spared $36.6 \pm 2.3 \%$ of the hippocampus and $43.7 \pm 5.9 \%$ of the subiculum (ventral lesions) and $39.1 \pm 1.5 \%$ of the hippocampus and $60.1 \pm 3.3 \%$ of the subiculum (dorsal lesions). The border between damaged and healthy tissue was sharp. None of the rats had significant damage outside the hippocampus, except around the cannula tracks in the overlying neocortex. We did not observe damage to the amygdala, the amygdalohippocampal transition area, or the entorhinal cortex (Fig. 1C-F).

\section{Corticosterone levels after mild stress}

To determine whether the hippocampus influenced corticosterone secretion during mild stress, we first measured the concentration of corticosterone in blood plasma after rats had spent 20 min in a brightly lit Perspex box to which they had already been exposed daily for 1 week. Corticosterone concentrations 2-3 min after the rat was removed from the test chamber ranged from 128 $\mathrm{ng} / \mathrm{ml}$ (mean of rats with ventral hippocampal lesions) to 226 $\mathrm{ng} / \mathrm{ml}$ (mean of sham-operated group). The corticosterone level in rats with complete or partial lesions of the hippocampus was not higher than in controls (Fig. $2 \mathrm{~A}$ ). In fact, corticosterone was lower after hippocampal damage than after sham surgery (group effect: $\left.F_{(3,61)}=6.0 ; p=0.001\right)$. Post hoc analyses showed that this effect reflected a reduction of corticosterone in rats with complete or ventral hippocampal lesions compared with shamoperated rats, as well as a reduction in animals with ventral lesions compared with those with dorsal lesions [Tukey honestly significant difference (HSD); $p<0.05$ ]. There was no significant correlation between corticosterone concentration and percentage damage to the hippocampus $\left(r_{(49)}=-0.06\right)$ or the subiculum $\left(r_{(49)}=-0.20\right)$.

\section{Corticosterone levels after moderate stress}

Seven days later, corticosterone responses were examined during increased stress in the same animals (Fig. 2B). The rats were placed in the Perspex box on 2 consecutive days. On day 1, they received three electric shocks to the foot. All animals responded with a significant increase in freezing (Fig. 3). On day 2, the rats were reintroduced to the chamber for $20 \mathrm{~min}$. No shock was given on this trial. Sham-operated rats and rats with partial lesions of the hippocampus showed strong freezing. Rats with complete lesions also froze more, but the freezing was temporary (group effect: $F_{(3,49)}=4.8, p=0.005$; group $\times$ time: $F_{(12,196)}=2.4, p<$ 0.01 ) (Fig. 3). Blood samples were collected $2-3 \mathrm{~min}$ after the rats were removed from the chamber on day 2 . The secretion of corticosterone increased significantly compared with the test before shock (Fig. $2 A, B)$ (trial effect: $F_{(1,60)}=14.9, p<0.001$ ), but the increase was independent of group (trial $\times$ group: $F_{(3,60)}=1.4$, $p>0.05)$. Corticosterone secretion was again slightly lower after hippocampal damage (Fig. $2 B$ ) (group effect: $F_{(3,60)}=3.9, p=$ $0.01)$. Group averages ranged from $157 \mathrm{ng} / \mathrm{ml}$ (complete lesions) to $289 \mathrm{ng} / \mathrm{ml}$ (sham-operated group). The group effect was caused primarily by lower concentrations in the complete hippocampal lesion group than in the sham-operated group (Tukey HSD; $p<0.01)$. Other pairwise comparisons were not significant. There was no correlation between corticosterone and percentage damage to the hippocampus or the subiculum $\left(r_{(48)}=\right.$ -0.17 and $r_{(48)}=-0.22$, respectively).

\section{Resting levels of corticosterone}

Finally, we examined whether hippocampal lesions influenced the resting level of plasma corticosterone in the same set of animals. Rats were retrieved directly from their home cages in the 

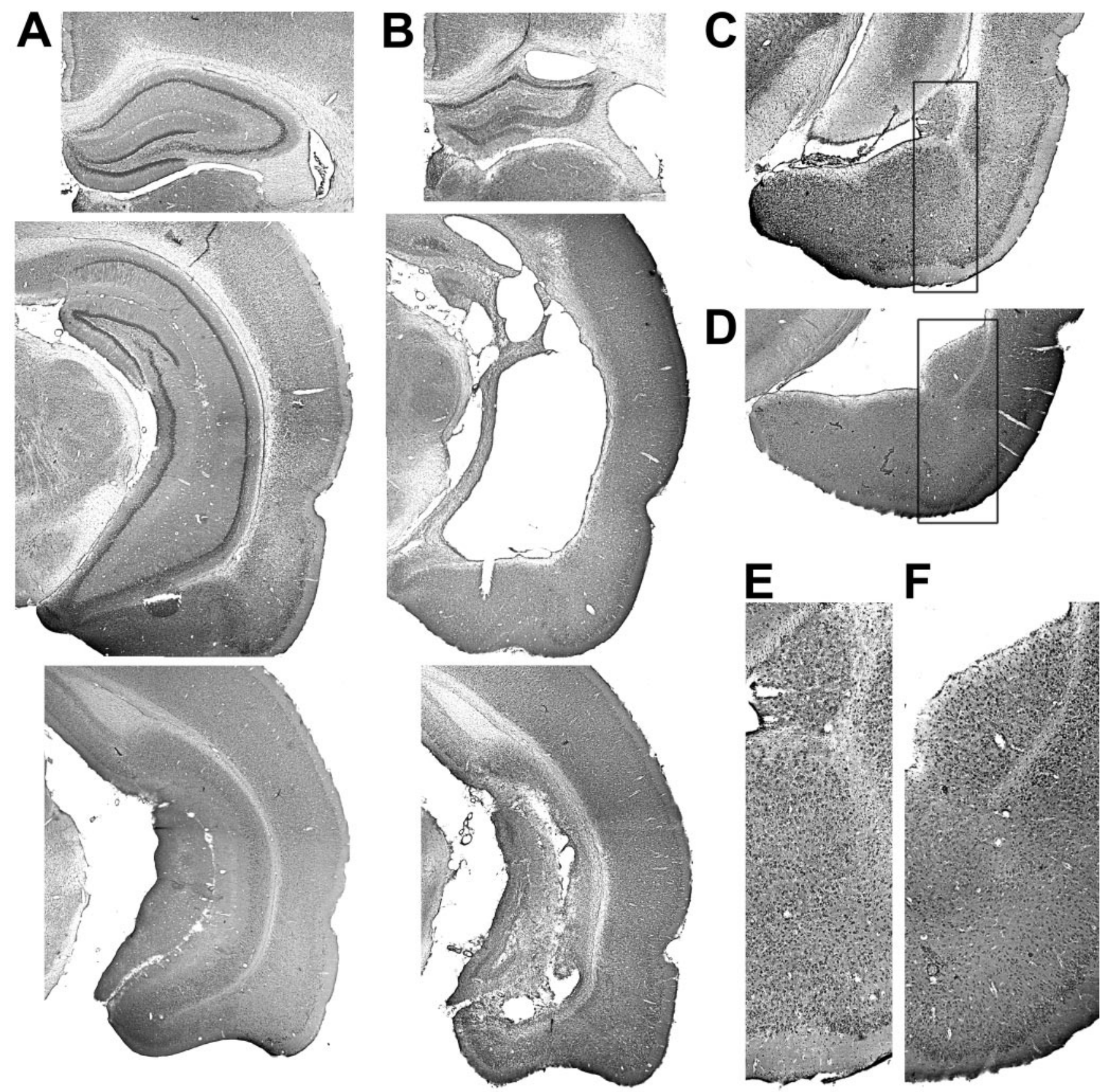

Figure 1. Representative cresyl violet stains of remaining neuronal cell bodies at four coronal levels in a sham-operated rat $(A, C, E)$ and a rat with a complete lesion of the hippocampus and substantial damage to the subiculum $(B, D, F) . C-F$ show lateral, basolateral, and cortical nuclei of the amygdala, as well as adjacent piriform cortex, near the ventral tip of the hippocampus. Boxes in $C$ and $D$ are shown at high magnification in $E$ and $F$, respectively.

vivarium and transported to the procedure bench for collection of blood. The transport took 10-12 sec. The corticosterone level was low in all groups, with averages ranging from 40 to $90 \mathrm{ng} / \mathrm{ml}$ (Fig. 2C), which is comparable with resting levels reported for Long-Evans rats in several other studies (Sapolsky et al., 1984; Bizon et al., 2001). Hippocampal damage did not increase adrenocortical activity. The concentration of corticosterone was numerically lower in animals with complete hippocampal lesions than in the control group, but the group differences did not reach statistical significance (one-way ANOVA; $F_{(3,40)}=2.76, p>$ 0.05). Resting corticosterone concentrations did not correlate with damage to the subiculum $\left(r_{(32)}=0.03\right)$ but were inversely related to the size of the hippocampal lesion $\left(r_{(32)}=-0.40 ; p<\right.$
$0.05)$. Corticosterone secretion in the home cage was significantly lower than in the Perspex box (before shock: $F_{(1,40)}=65.1, p<$ 0.001; after shock: $\left.F_{(1,39)}=57.1, p<0.001\right)$.

\section{Replication of previous stress protocols}

One reason why our lesions failed to affect adrenocortical activity could be that the behavioral tasks were less stressful than, or in other ways differed from, those of previous studies. To examine this possibility, we copied two of the behavioral procedures used in studies that reported hypersecretion of corticosterone after hippocampal damage. Immobilization is probably the most commonly used type of stress in these studies. Thus, the concentration of corticosterone in blood plasma was measured in rats ex- 


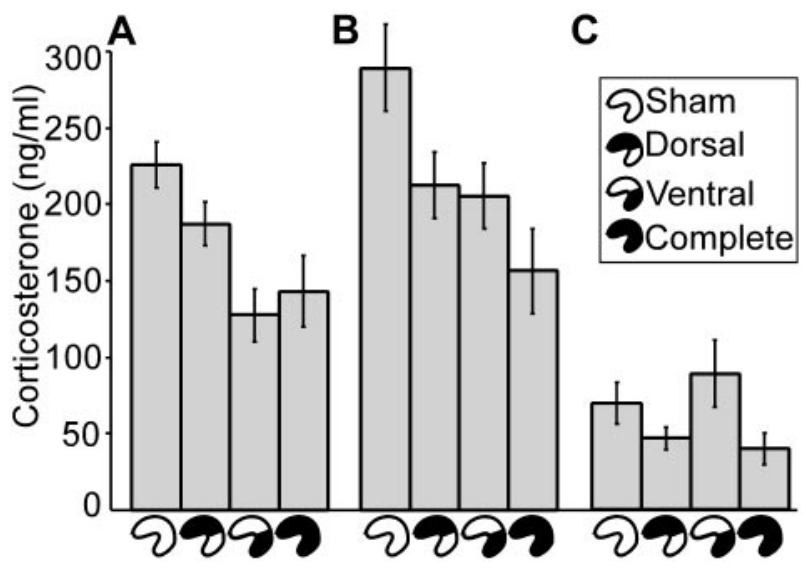

Figure 2. Plasma concentrations of corticosterone (means \pm SEM) in rats with complete hippocampal lesions, lesions of the dorsal or ventral hippocampus, or sham lesions. Corticosterone concentrations were determined after confinement to a familiar but brightly lit Perspex box $(A, B)$ or after rest in the vivarium ( $C$. Samples in $B$ were collected $24 \mathrm{hr}$ after the animals received an electric shock in the Perspex box.

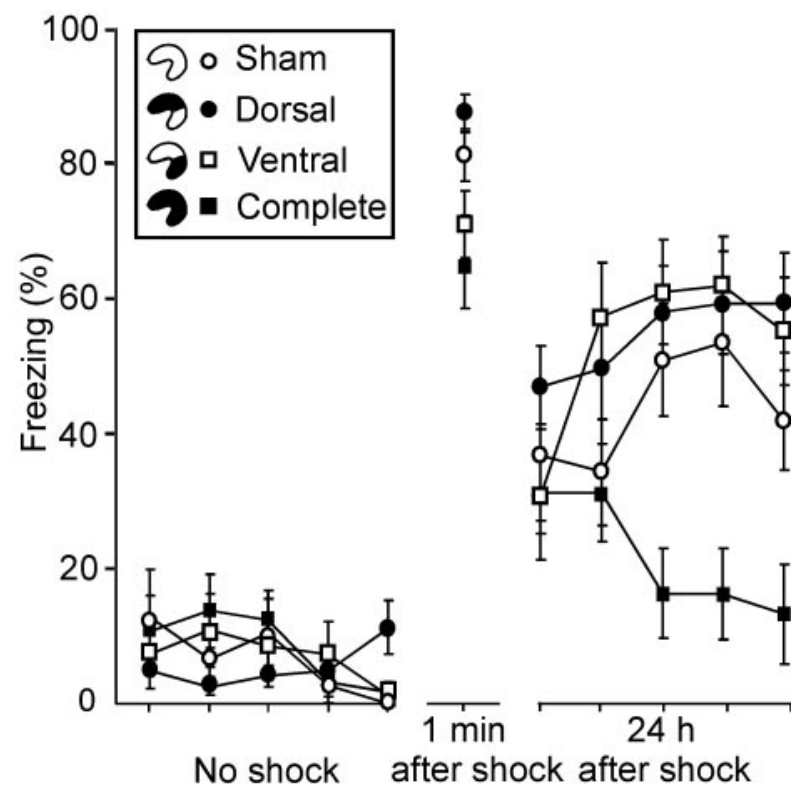

Figure 3. Freezing in response to electric foot shock after complete or partial (dorsal or ventral) hippocampal lesions. The diagram shows the percentage of time spent freezing before and after electric shock (segments of $1 \mathrm{~min}$; sample interval $10 \mathrm{sec}$; means \pm SEM). Even rats with complete hippocampal lesions exhibited increased freezing on the $24 \mathrm{hr}$ retention test, although the response was temporary.

posed to $1 \mathrm{hr}$ of restraint stress, as for example in Sapolsky et al. (1984). Blood was collected immediately after the rats were released. Again, corticosterone concentrations were similar in the hippocampal group and the sham group (mean values of 284 and $278 \mathrm{ng} / \mathrm{ml}$, respectively; $t_{(14)}=0.1 ; p>0.05$ ) (Fig. $4 A$ ). These values are comparable with those measured after the shock retention test.

The same animals were subsequently trained to find a hidden platform in a Morris water maze. The training procedure was similar to the one reported by Roozendaal et al. (2001), with $2 \mathrm{~d}$ of four training trials and a probe trial on the third day. Blood was sampled immediately after the probe trial. As expected, rats with hippocampal lesions had longer escape latencies than shamoperated animals (group effect: $F_{(1,13)}=9.9, p<0.01$; mean

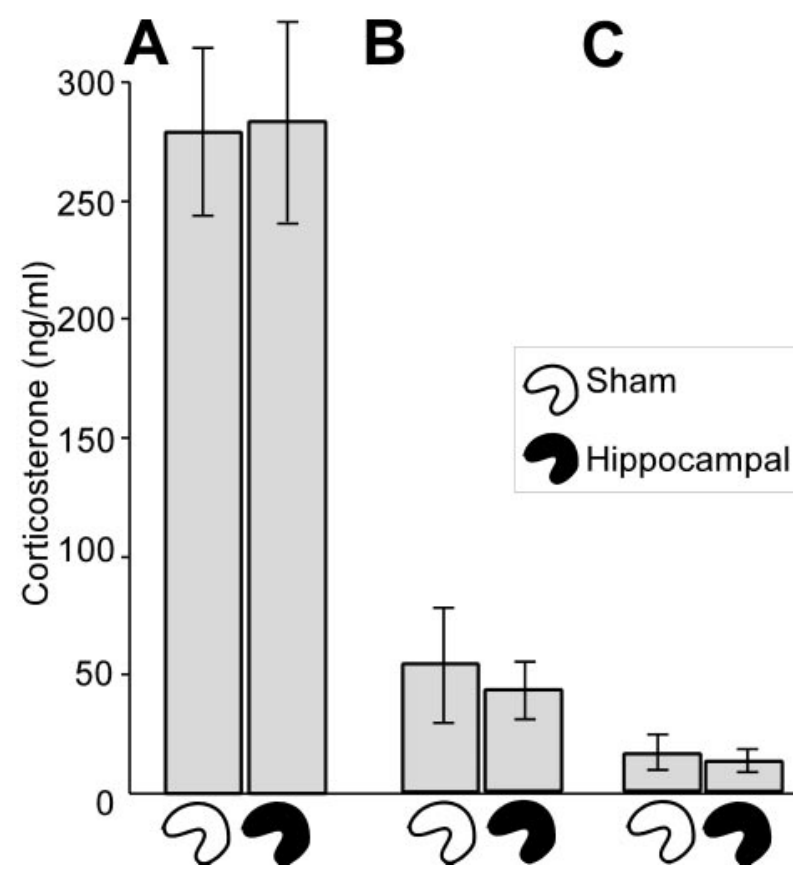

Figure 4. Plasma concentrations of corticosterone (means \pm SEM) in rats with complete hippocampal lesions or sham lesions. Corticosterone concentrations were determined in the same animals after $1 \mathrm{hr}$ of restraint stress $(A)$, after $1 \mathrm{~min}$ of swimming in a water maze $(B)$, or after rest in the vivarium ( $C$ ). The behavioral procedures in $A$ and $B$ were similar to those reported by Sapolsky et al. (1984) and Roozendaal et al., (2001), respectively.

escape latencies on day 2: $36.8 \pm 4.2$ and $18.4 \pm 2.8 \mathrm{sec}$, respectively). Quadrant differences were not significant on the probe trial (time in target quadrant: $10.7 \pm 2.9$ and $16.1 \pm 2.5 \mathrm{sec}$ in hippocampal and sham-operated rats, respectively; quadrant effect: $F_{(3,39)}=1.5$; quadrant $\times$ group effect: $F_{(3,39)}=1.7, p>$ 0.05). As in the Roozendaal study, corticosterone concentrations were determined after the final probe trial. It took $\sim 5 \mathrm{~min}$ from the time the rats were picked up in the vivarium until the probe trial was completed and the rat was brought to the procedure bench for blood sampling. There was no difference in corticosterone concentration under these conditions (mean values of 43 and $54 \mathrm{ng} / \mathrm{ml}$ in hippocampal and sham-operated rats, respectively; $\left.t_{(12)}=0.4 ; p>0.05\right)$ (Fig. $4 B$ ). The concentrations were lower than with the other stress procedures, presumably because corticosterone was sampled well before the peak values were attained.

Resting levels of corticosterone were determined in the same animals $5 \mathrm{~d}$ after the water-maze study. As in the previous experiments, there was no difference between hippocampal and shamoperated animals (mean values of 16 and $12 \mathrm{ng} / \mathrm{ml}$ in hippocampal and sham-operated rats, respectively; $t_{(11)}=0.3 ; p>0.05$ ) (Fig. 4C).

\section{Duration of corticosterone response}

Lesions in the hippocampal formation may prolong the corticosterone response in addition to enhancing the peak concentration (Sapolsky et al., 1984; Herman et al., 1995). We were concerned that our blood samples, collected only a few minutes after the stress event, had missed a potentially delayed corticosterone hypersecretion in the hippocampal lesion group. Thus, we prepared a separate batch of animals ( 10 with complete hippocampal lesions and 9 with sham lesions) in which the concentration of corticosterone was measured in blood from vena jugularis at sev- 


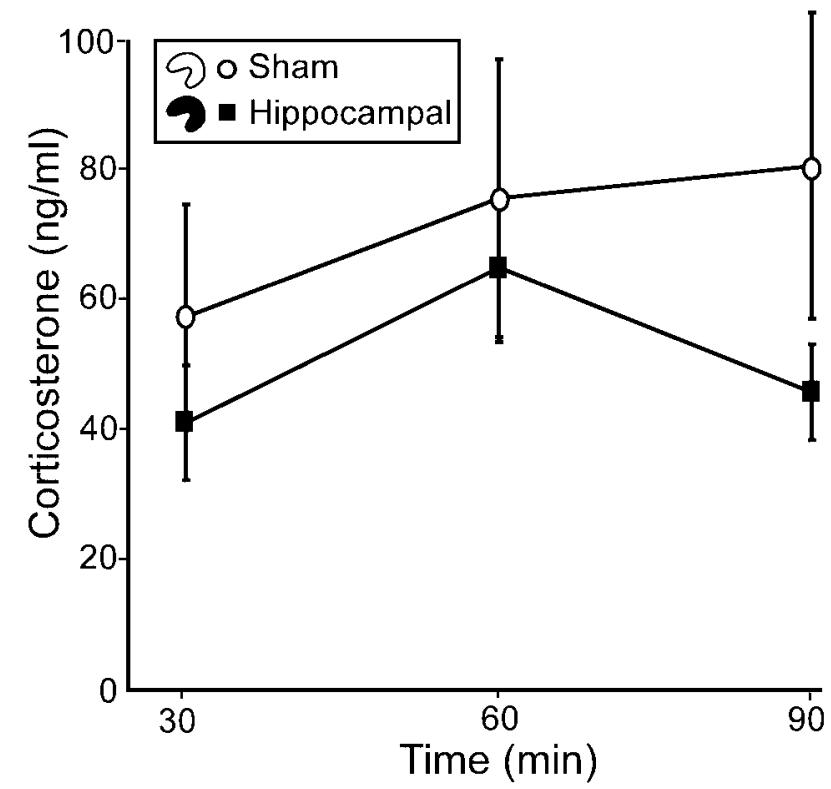

Figure 5. Corticosterone response at different latencies after exposure to a stressor in rats with complete hippocampal lesions or sham lesions. Corticosterone concentrations (means \pm SEM) were determined 30,60 , or 90 min after exposure to the brightly lit Perspex box.

eral later time points. Blood was collected either 30, 60, or 90 min after the rats were put in the brightly lit Perspex box. The animals spent $5 \mathrm{~min}$ in the box and the rest of the interval in the vivarium. There was no evidence of corticosterone hypersecretion in the hippocampal group at any time point. Again, the corticosterone level was consistently lower in the lesioned animals (Fig. 5) (group: $\left.F_{(1,16)}=6.6 ; p<0.05\right)$. There was no significant effect of time $(F<1)$ and no significant groups $\times$ time interaction $(F<$ 1 ). The absolute concentrations of corticosterone were low (Fig. 5), suggesting that confinement in the box caused a short-lasting activation $(<30 \mathrm{~min})$ in both groups. With longer confinements (Fig. 6) (see below), corticosterone levels were higher, but there was no difference between the hippocampal group and the sham group at either 30 or $90 \mathrm{~min}$.

\section{Nonspecific effects of surgery}

Surgery may influence the HPA system in nonspecific ways. Such influences could potentially mask any specific effects of lesions in the hippocampus. To estimate the presence of nonspecific changes, we compared resting corticosterone levels in rats with sham lesions $(n=8)$ with those of naive, unoperated rats from the same litter $(n=8)$. Blood was collected $14 \mathrm{~d}$ after the sham group was operated. There was no difference in corticosterone levels (sham group: $37 \pm 14 \mathrm{ng} / \mathrm{ml}$; unoperated group: $35 \pm 17$ $\left.\mathrm{ng} / \mathrm{ml} ; t_{(13)}=0.1 ; p>0.05\right)$. Thus, it is unlikely that the surgical trauma affected adrenocortical activity at the time of testing.

\section{Effect of recovery after surgery}

It is possible that the lack of hypersecretion in the hippocampal group reflected functional recovery after surgery caused by plasticity in the HPA axis or suprahypothalamic control systems (Jacobson and Sapolsky, 1991; Sapolsky et al., 1991) and that disinhibition of corticosterone secretion would be expressed at shorter intervals between lesion and test. In the above experiments, recovery intervals varied between 10 and $29 \mathrm{~d}$. It is possible that these intervals were too long to detect a possible effect on adrenocortical hyperactivity. To determine the effect of recovery

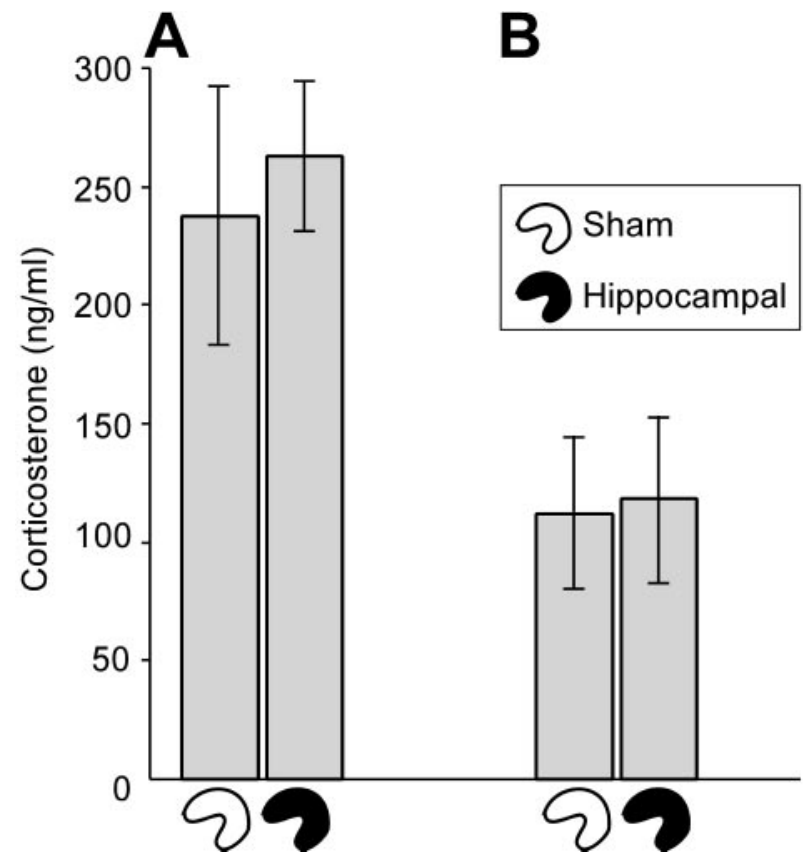

Figure 6. Corticosterone response during the first week after hippocampal ablation. Rats with complete hippocampal lesion or sham surgery were exposed to a brightly lit novel chamber for either $30 \mathrm{~min}(A)$ or $90 \mathrm{~min}(B)$. Corticosterone concentrations (means $\pm \mathrm{SEM}$ ) were determined immediately after removal from the environment

time, we conducted two additional experiments. First, we shortened the recovery time after the induction of lesions. Blood was sampled after placement in two novel chambers 4 and $7 \mathrm{~d}$ after surgery, respectively. The pattern of results was comparable with that of the other experiments. Corticosterone levels were higher after 30 min of confinement than at 90 min (Fig. 6) (time: $F_{(1,13)}$ $=9.0 ; p=0.01$ ), but there was no difference between the hippocampal group and the sham group at any time (group: $F_{(1,13)}<$ 1 ; group $\times$ time: $\left.F_{(1,13)}<1\right)$.

In a second experiment, recovery was eliminated entirely by inactivating the hippocampus temporarily using local infusion of the $\mathrm{GABA}_{\mathrm{A}}$ receptor agonist muscimol. Histological examination showed that all implanted cannulas hit the hippocampus as intended (Fig. $7 A, B$ ). Extrahippocampal damage was limited to the neocortex around the guide cannulas. To determine whether the $\mathrm{GABA}_{\mathrm{A}}$ receptor agonist muscimol infusions inactivated hippocampal function as intended, we pretrained rats to find a hidden escape platform at a fixed location in a hippocampaldependent water-maze task (Morris et al., 1982). Before infusion, the rats were given a probe trial in which the platform was submerged and thus unavailable to the rat. All rats showed a strong bias toward the target location (Fig. $8 \mathrm{~A}$ ). One hour after drug infusion, retention was probed a second time. Although the saline-injected control animals maintained their preference for the platform region, there was no bias toward the platform location in animals that received muscimol at two locations in each hippocampus (Fig. 8 B). Infusions at a single location did not lead to significant impairment of retention. There was a significant effect of groups on time spent in the target zone $\left(F_{(2,29)}=5.6 ; p<\right.$ $0.01)$, which reflected the impairment of the double-infused group compared with the two other groups (Tukey HSD; $p<$ $0.01)$. At the end of the probe trial, the platform was raised at a new location opposite to the one used during training, and the rats were trained with this location on the next eight trials. A final probe trial replicated the pattern on the previous retention test 

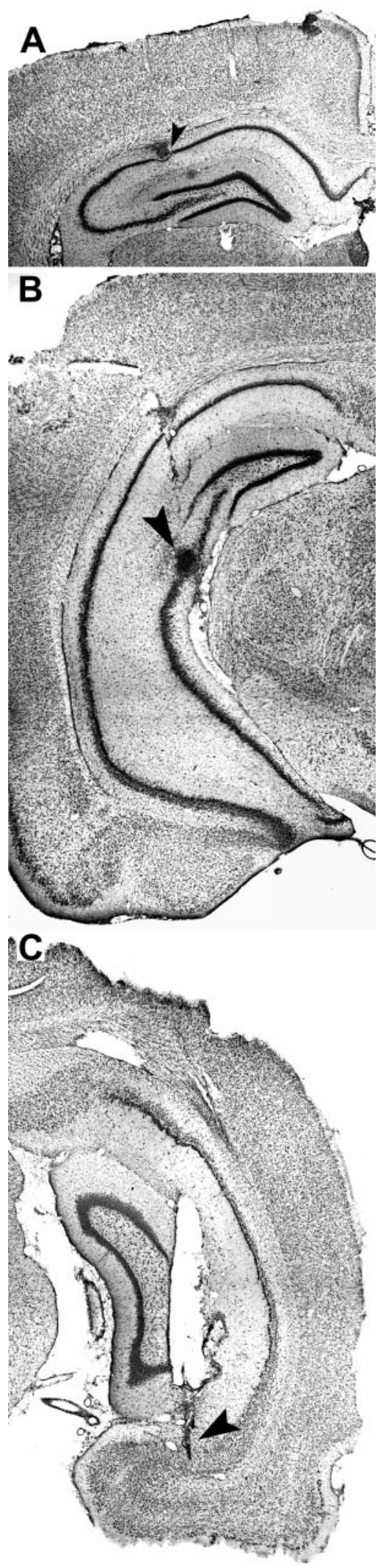

Figure 7. Cresyl violet stains showing position of cannulas for infusion into hippocampus ( $A$, $B)$ (rat with two cannulas per hippocampus) or ventral subiculum ( $C$ ). The injection volume per cannula was $0.25 \mu \mathrm{l}$ (hippocampus) or $0.40 \mu \mathrm{l}$ (subiculum). Arrowheads indicate approximate center of infusion.
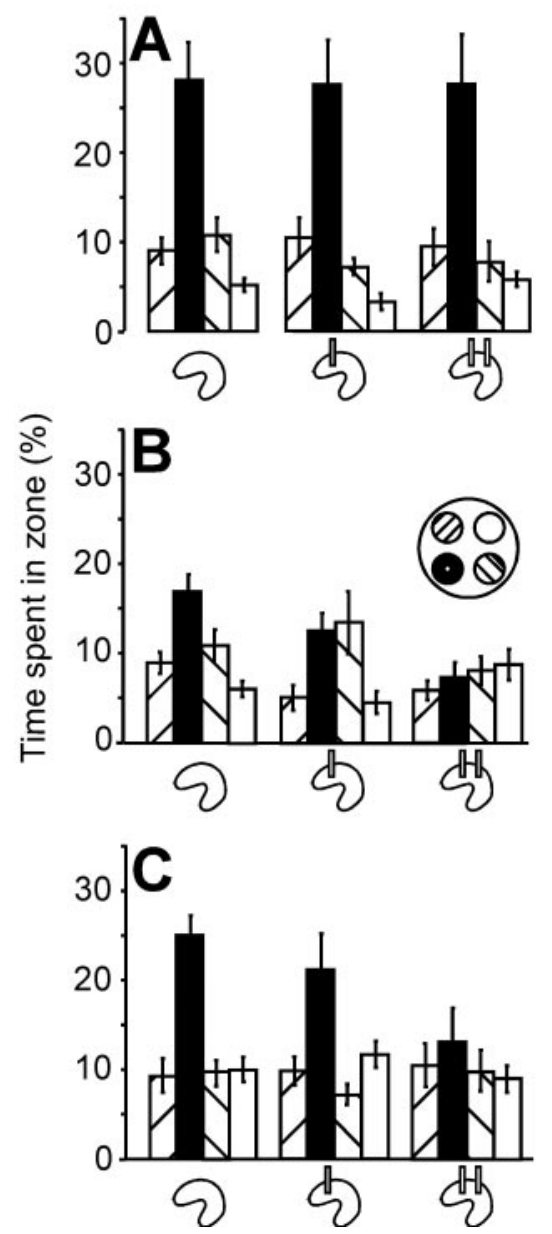

Figure 8. Effect of temporary inactivation of the hippocampus on a known hippocampal function: retention in a Morris water maze. The hippocampus was inactivated by microinfusion of the $G_{A B A_{A}}$ receptor agonist muscimol; before infusion $(A), 1 \mathrm{hr}$ after infusion $(B)$, or after new learning with a different platform position ( $2 \mathrm{hr}$ after infusion) ( () . The diagrams show time spent in the central zone of the platform quadrant (black) and in corresponding zones of the three other quadrants (means \pm SEM) for sham-operated rats, rats with a single infusion in each hippocampus, and rats with two infusions in each hippocampus. Note that both retention and new learning were impaired by infusions that targeted the hippocampus at two locations.

(Fig. $8 C)\left(F_{(2,29)}=4.1 ; p<0.05\right)$. Again, the double-infused group differed from each of the two other groups (Tukey HSD; $p<0.05)$. Thus, muscimol disrupted both retention and new learning in the water maze, implying that significant amounts of hippocampal tissue were inactivated $1 \mathrm{hr}$ after the infusion.

Two days after the retention test, the infusion procedure was repeated. The rats rested for $1 \mathrm{hr}$ in the vivarium after the infusion. Within a period of $2-3 \mathrm{~min}$, they were then anesthetized, and blood was sampled from the heart before the rats were perfused. The concentrations were slightly higher in this study than the resting levels in the lesion experiment, but the increase was expressed in all groups (group averages of $88-129 \mathrm{ng} / \mathrm{ml}$ ) and might be an aftereffect of the infusion $1 \mathrm{hr}$ earlier (Fig. 9). More importantly, there was no difference in mean corticosterone concentration in muscimol- and saline-infused animals (Fig. 9A) $\left(F_{(2,29)}<1 ; p>0.05\right)$. The assumption of normality was strongly violated in this analysis because of one extreme outlier in one of the muscimol groups (Fig. 9B). However, a nonparametric test gave similar results (Kruskal-Wallis test: $\chi^{2}=1.37 ; \mathrm{df}=2 ; p>$ 0.50 ). The median corticosterone concentration of the doubleinfused muscimol group was comparable with that of the sham 


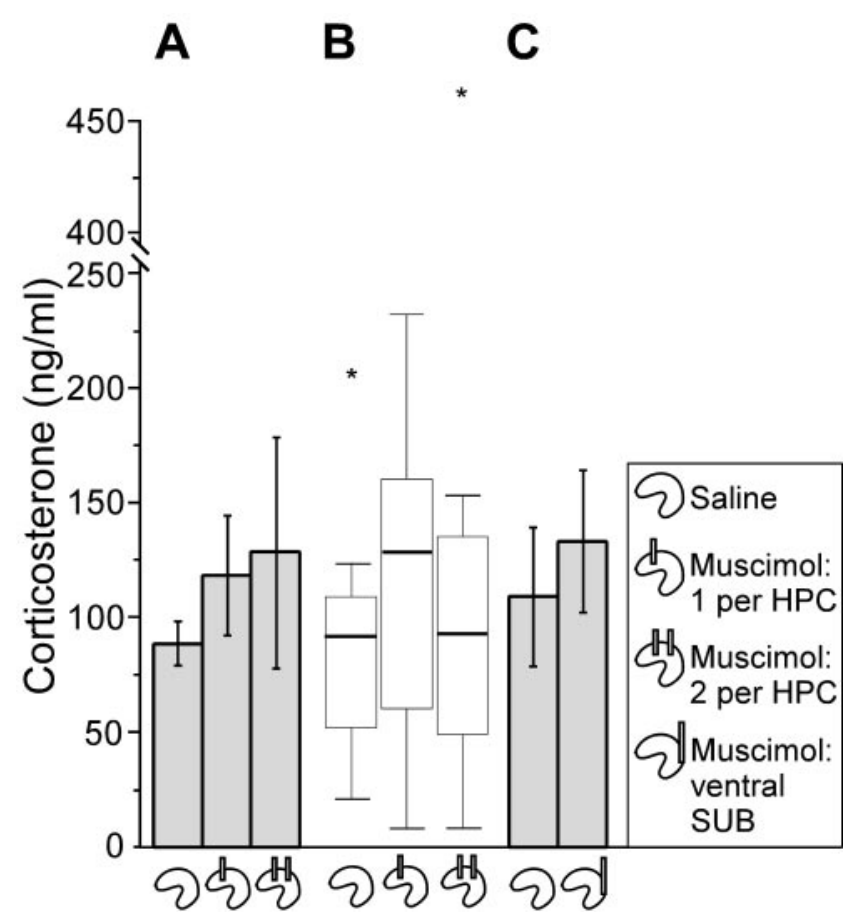

Figure 9. Plasma concentration of corticosterone $1 \mathrm{hr}$ after temporary inactivation of the hippocampus $(A, B)$ or the ventral subiculum $(C)$ by the $G_{A B A_{A}}$ receptor agonist muscimol. The rats rested in the vivarium between infusion and blood collection. $A, C$, Mean $\pm \mathrm{SEM} ; B$, box plot. Medians are indicated by thick horizontal lines inside the interquartile boxes. Asterisks indicate outliers.

group (Fig. 9B). Thus, inactivation of the hippocampus failed to elevate adrenocortical activity significantly even at time scales that were too short for functional recovery and plasticity.

It is possible that influences of the hippocampal formation on HPA activity are mediated by the ventral subiculum rather than the hippocampus proper (Herman et al., 1995, 1998). Thus, in a second inactivation experiment, muscimol was infused bilaterally into the ventral subiculum. Inactivation did not significantly elevate the resting levels of corticosterone, although there was a small numerical increase (ventral subiculum group: $133 \mathrm{ng} / \mathrm{ml}$; saline group: $109 \mathrm{ng} / \mathrm{ml} ; t_{(9)}=0.8$; $p>0.05$; paired $t$ test) (Fig. $9 C$ ). The opening of the cannula was placed at the border between the dentate gyrus and the underlying ventral subiculum $(n=5)$ or within the ventral subiculum more caudally $(n=5)$ (Fig. $7 C$ ). In two animals, the tip of the cannula was outside the target area in one hemisphere (entorhinal cortex and presubiculum and parasubiculum, respectively). Excluding these animals did not increase the difference between the groups.

\section{Discussion}

The main finding was that corticosterone secretion was not increased by complete axon-sparing lesions of the hippocampus. Corticosterone was measured at the nadir of the rat circadian cycle of corticosterone secretion when the hypersecretion is maximal after nonselective lesions (Moberg et al., 1971; Fischette et al., 1980). All animals responded with elevated corticosterone levels after stress, but the concentrations did not increase more in lesioned animals than in control-operated animals at any of the time points tested or with any of the behavioral procedures that we used. In fact, in several experiments, the secretion of corticosterone was slightly reduced after complete damage to the hip- pocampus. This reduction may be related to attenuated fear responses in rats with hippocampal lesions (Deacon et al., 2002; Kjelstrup et al., 2002). We also failed to see an increase in corticosterone secretion after short recovery periods and temporary inactivation of the hippocampus or the ventral subiculum, suggesting that the maintenance of normal adrenocortical activity after lesions of these structures did not depend on functional recovery or compensatory processes in the hypothalamus or in suprahypothalamic control systems. Altogether, our findings indicate that the hippocampus is not necessary for preventing excessive adrenocortical activity.

Corticosterone secretion was not exacerbated by hippocampal lesions either during rest or after exposure to stressors of different intensity. It can be argued that the hippocampal group had normal corticosterone concentrations in the shock retention study because they did not recall the aversive experience. However, these rats did exhibit a temporary increase in freezing, consistent with previous reports suggesting that retention of contextual information is mostly spared when the hippocampus is damaged before training (Maren et al., 1997). Rats with lesions of either the dorsal two-thirds or the ventral two-thirds of the hippocampus froze as much as the sham-operated control rats but showed no further increase in corticosterone concentration. Thus, the absence of hypersecretion in the hippocampal groups after electric shock was probably not caused by impaired retention.

These results contrast with reports of adrenocortical hyperactivity after large nonselective mechanical or electrolytic lesions of the hippocampus (Fendler et al., 1961; Kim and Kim, 1961; Knigge, 1961; Moberg et al., 1971; Murphy et al., 1979; Fischette et al., 1980; Wilson et al., 1980; Sapolsky et al., 1984, 1991; Herman et al., 1989). Discrepant effects on corticosterone secretion after hippocampal lesions have previously been attributed to differences in recovery time between surgery and experimentation (Jacobson and Sapolsky, 1991). This was suggested on the basis of the observation that monkeys recover from adrenocortical hyperactivity within 15 months after hippocampal damage (Sapolsky et al., 1991). The durability of the adrenocortical hyperactivity cannot be extrapolated to rats, but a study by Lengvari and Halasz (1973) suggested that recovery occurs at a faster time scale in the rat. These authors observed that lesions of the fornix disrupted the circadian corticosterone rhythm 1 week, but not 3 weeks, after surgery. However, there was no significant enhancement of absolute corticosterone levels at any time point; in fact, the lesioned group failed to attain the high levels of corticosterone shown by control rats at the beginning of the dark period. Our own results with short recovery periods after surgery (down to $4 \mathrm{~d}$ ) and temporary inactivation by muscimol suggest that failure to see adrenocortical hyperactivity after hippocampal damage cannot be attributed solely to the timing of the experiments.

The maintenance of normal adrenocortical activity after axon-sparing interventions suggests a different explanation. The previously reported increase in corticosterone concentration may reflect disruption of fibers passing through or around the lesioned area. The failure of other studies to determine such an effect (Coover et al., 1971; Lanier et al., 1975; Conforti and Feldman, 1976; Smotherman et al., 1981; Bradbury et al., 1993; Herman et al., 1995) may not have been a reflection of incomplete damage to the hippocampus. One possibility is that nonselective mechanical or electrolytic lesions of the hippocampus disrupted rostrally oriented fibers from the ventral subiculum. The ventral subiculum, unlike the hippocampus itself, has extensive bisynaptic connections with the paraventricular nucleus of the hypothal- 
amus (Risold and Swanson, 1997; Petrovich et al., 2001), and ibotenate lesions in the ventral subiculum are associated with elevated corticosterone responses (Herman et al., 1995, 1998). Two observations speak against a unique role for the ventral subiculum in tonic inhibition of the HPA axis. First, our lesions were accompanied by substantial damage to the subiculum, without detectable effects on corticosterone levels. The remaining subicular tissue ( $15 \%$ on average) was probably not sufficient to support inhibition of adrenocortical activity. Second, resting corticosterone levels were not significantly increased by temporary inactivation of the ventral subiculum. It is unlikely, however, that the infusions inactivated the structure completely, and it is possible that pronounced differences appear under more stressful conditions (Herman et al., 1995). Nonetheless, the most parsimonious interpretation of the lesion and inactivation data as a whole is that the hippocampal formation operates in parallel with other suprahypothalamic control systems and that these other systems are sufficient, under most circumstances, to prevent excessive HPA activity. High densities of glucocorticoid receptors are present in several extrahippocampal structures, such as the prefrontal cortex, the lateral septum, the bed nucleus of the stria terminalis, and the paraventricular nucleus itself, and projections from these areas to the HPA axis are likely to provide additional negative feedback inhibition (Herman and Cullinan, 1997). The present data suggest that under many conditions these systems may be able to control HPA activity in the absence of hippocampal-subicular integrity.

Disruption of bypassing fibers does not explain the discrepancy between the present results and those of Roozendaal et al. (2001), who observed stress-induced hypersecretion of corticosterone after a water-maze probe trial in rats with kainateinduced lesions in area CA3 of the dorsal hippocampus. It is possible that dishinhibition of HPA activity is expressed only at high stress levels and that the Roozendaal task was particularly stressful. However, using the same behavioral protocol as Roozendaal et al. (2001), we failed to see an increase in corticosterone concentrations after the probe trial in rats with hippocampal lesions. The most striking procedural difference between the studies is the choice of neurotoxins (kainic acid vs ibotenic acid). Kainic acid is known to cause recurrent epileptic seizures even after nanogram infusions in the hippocampus (French et al., 1982; Bouilleret et al., 1999), and such seizures may lead to structural or functional damage in hippocampal target areas. It remains to be determined whether extrahippocampal damage or other factors account for the different effects on adrenocortical activity. Our results with lesions and temporary inactivation certainly do not rule out an influence by the hippocampus on the HPA axis but suggest that multiple brain systems may be capable of exerting independent tonic inhibition of the HPA axis.

\section{References}

Aronsson M, Fuxe K, Dong Y, Agnati LF, Okret S, Gustafsson JA (1988) Localization of glucocorticoid receptor mRNA in the male rat brain by in situ hybridization. Proc Natl Acad Sci USA 85:9331-9335.

Arriza JL, Simerly RB, Swanson LW, Evans RM (1988) The neuronal mineralocorticoid receptor as a mediator of glucocorticoid response. Neuron 1:887-900.

Bizon JL, Helm KA, Han JS, Chun HJ, Pucilowska J, Lund PK, Gallagher M (2001) Hypothalamic-pituitary-adrenal axis function and corticosterone receptor expression in behaviourally characterized young and aged Long-Evans rats. Eur J Neurosci 14:1739-1751.

Bouilleret V, Ridoux V, Depaulis A, Marescaux C, Nehlig A, Le Gal La Salle G (1999) Recurrent seizures and hippocampal sclerosis following intrahip- pocampal kainate injection in adult mice: electroencephalography, histopathology and synaptic reorganization similar to mesial temporal lobe epilepsy. Neuroscience 89:717-729.

Bradbury MJ, Strack AM, Dallman MF (1993) Lesions of the hippocampal efferent pathway (fimbria-fornix) do not alter sensitivity of adrenocorticotropin to feedback inhibition by corticosterone in rats. Neuroendocrinology 58:396-407.

Brett LP, Chong GS, Coyle S, Levine S (1983) The pituitary-adrenal response to novel stimulation and ether stress in young adult and aged rats. Neurobiol Aging 4:133-138.

Conforti N, Feldman S (1976) Effects of dorsal fornix section and hippocampectomy on adrenocortical responses to sensory stimulation in the rat. Neuroendocrinology 22:1-7.

Coover GD, Goldman L, Levine S (1971) Plasma corticosterone levels during extinction of a lever-press response in hippocampectomized rats. Physiol Behav 7:727-732.

Deacon RMJ, Bannerman DM, Rawlins JNP (2002) Anxiolytic effects of cytotoxic hippocampal lesions in rats. Behav Neurosci 116:884-901.

Fendler K, Karmos G, Telegdy G (1961) The effect of hippocampal lesion on pituitary-adrenal function. Acta Physiol (Budapest) 20:283-297.

Fischette CT, Komisaruk BR, Edinger HM, Feder HH, Siegel A (1980) Differential fornix ablations and the circadian rhythmicity of adrenal corticosteroid secretion. Brain Res 195:373-387.

French ED, Aldinio C, Schwarcz R (1982) Intrahippocampal kainic acid, seizures and local neuronal degeneration: relationships assessed in unanesthetized rats. Neuroscience 7:2525-2536.

Herman JP, Cullinan WE (1997) Neurocircuitry of stress: central control of the hypothalamo-pituitary-adrenocortical axis. Trends Neurosci 20:78-84.

Herman JP, Schafer MK, Young EA, Thompson R, Douglass J, Akil H, Watson SJ (1989) Evidence for hippocampal regulation of neuroendocrine neurons of the hypothalamo-pituitary-adrenocortical axis. J Neurosci 9:3072-3082.

Herman JP, Cullinan WE, Morano MI, Akil H, Watson SJ (1995) Contribution of the ventral subiculum to inhibitory regulation of the hypothalamopituitary-adrenocortical axis. J Neuroendocrinol 7:475-482.

Herman JP, Dolgas CM, Carlson SL (1998) Ventral subiculum regulates hypothalamo-pituitary-adrenocortical and behavioural responses to cognitive stressors. Neuroscience 86:449-459.

Jacobson L, Sapolsky R (1991) The role of the hippocampus in feedback regulation of the hypothalamic-pituitary-adrenocortical axis. Endocr Rev 12:118-134.

Jarrard LE (1989) On the use of ibotenic acid to lesion selectively different components of the hippocampal formation. J Neurosci Methods 29:251-259.

Kim C, Kim C (1961) Effect of partial hippocampal resection on stress mechanisms in rats. Am J Physiol 201:337-343.

Kjelstrup KG, Tuvnes FA, Steffenach H-A, Murison R, Moser EI, Moser M-B (2002) Reduced fear expression after lesions of the ventral hippocampus. Proc Natl Acad Sci USA 99:10825-10830.

Knigge KM (1961) Adrenocorticoid response to stress in rats with lesions in the hippocampus and amygdala. Proc Soc Exp Biol Med 108:18-21.

Lanier LP, Van Hartesveldt C, Weis BJ, Isaacson RL (1975) Effects of differential hippocampal damage upon rhythmic and stress-induced corticosterone secretion in the rat. Neuroendocrinology 18:154-160.

Lengvari I, Halasz B (1973) Evidence for a diurnal fluctuation in plasma corticosterone levels after fornix transection in the rat. Neuroendocrinology 11:191-196.

Maren S, Aharonov G, Fanselow MS (1997) Neurotoxic lesions of the dorsal hippocampus and Pavlovian fear conditioning in rats. Behav Brain Res 88:261-274.

McEwen BS, Weiss JM, Schwartz LS (1968) Selective retention of corticosterone by limbic structures in rat brain. Nature 220:911-912.

Moberg GP, Scapagnini U, de Groot J, Ganong WF (1971) Effect of sectioning the fornix on diurnal fluctuation in plasma corticosterone levels in the rats. Neuroendocrinology 7:11-15.

Morris RGM, Garrud P, Rawlins JNP, O'Keefe J (1982) Place navigation impaired in rats with hippocampal lesions. Nature 297:681-683.

Moser M-B, Moser EI (1998) Functional differentiation in the hippocampus. Hippocampus 8:608-619. 
Murphy HM, Wideman CH, Brown TS (1979) Plasma corticosterone levels and ulcer formation in rats with hippocampal lesions. Neuroendocrinology 28:123-130.

Petrovich GD, Canteras NS, Swanson LW (2001) Combinatorial amygdalar inputs to hippocampal domains and hypothalamic behavior systems. Brain Res Rev 38:247-289.

Risold PY, Thompson RH, Swanson LW (1997) The structural organization of connections between hypothalamus and cerebral cortex. Brain Res Rev 24:197-254.

Roozendaal B, Phillips RG, Power AE, Brooke SM, Sapolsky RM, McGaugh JL (2001) Memory retrieval impairment induced by hippocampal CA3 lesions is blocked by adrenocortical suppression. Nat Neurosci 4:1169-1171.

Sapolsky RM, Krey LC, McEwen BS (1984) Glucocorticoid-sensitive hip- pocampal neurons are involved in terminating the adrenocortical stress response. Proc Natl Acad Sci USA 81:6174-6177.

Sapolsky RM, Zola-Morgan S, Squire LR (1991) Inhibition of glucocorticoid secretion by the hippocampal formation in the primate. J Neurosci 11:3695-3704.

Selye H (1936) A syndrome produced by diverse nocuous agents. Nature 148:84-85.

Smotherman WP, Kolp LA, Coyle S, Levine S (1981) Hippocampal lesion effects on conditioned taste aversion and pituitary-adrenal activity in rats. Behav Brain Res 2:33-48.

Wilson MM, Greer SE, Greer MA, Roberts L (1980) Hippocampal inhibition of pituitary-adrenocortical function in female rats. Brain Res 197: 433-441. 